\title{
Thermodynamic Approach to Cerebrospinal Fluid Circulation
}

\author{
Leszek Herbowski ${ }^{\mathrm{a}, \mathrm{c}}$, Henryk Gurgul ${ }^{\mathrm{b}}$
}

\begin{abstract}
Background: The authors present the thermodynamic approach to the cerebrospinal fluid circulation.

Methods: On the basis of skin temperature measurements in 16 healthy volunteers a $1.6 \pm 0.2{ }^{\circ} \mathrm{C}($ mean $\pm \mathrm{SD})$ difference between the frontal and the lumbar regions has been showed.

Results: Such a temperature difference between both ends of the subarachnoid space in the intracranial and the intracanal compartments can cause natural circulation of cerebrospinal fluid to reach a thermal equilibrium. The cerebrospinal fluid flow is a molecular motion as a consequence of the gravity force and the Brownian movements.
\end{abstract}

Conclusions: The Brownian motions are the driving forces for the cerebrospinal fluid bulk flow directed upwardly. The gravity force is the driving force for the cerebrospinal fluid bulk flow directed downwardly. The cerebrospinal fluid circulation in the spinal canal is like a corkscrew motion.

Keywords: Cerebrospinal fluid circulation; Skin temperature; Thermal equilibrium; Brownian motion; Gravity force

Manuscript accepted for publication December 12, 2011

${ }^{a}$ Neurosurgery Department, Public Provincial Hospital Complex,

Arkonska 4, 71-455, Szczecin, Poland

${ }^{b}$ Chair of Sea and Environmental Physics, Institute of Physics, University of Szczecin, Poland

${ }^{\mathrm{c}}$ Corresponding author: Leszek Herbowski.

Email: leszekherbowski@data.pl

doi:10.4021/jnr77w

\section{Introduction}

In healthy people an average temperature of different thermal regions can vary even by $2-4{ }^{\circ} \mathrm{C}[1,2]$. It is assumed that the mean skin surface temperature difference of $0.5^{\circ} \mathrm{C}$ is a diagnostically significant value of a clinically meaningful thermographic abnormality [3]. Only asymmetrical and transversal changes of skin temperatures are very well described especially in pain disorders [4]. What is more important, however, is the fact that the skin temperature is a dynamic phenomenon and the temperature skin distribution in relation to individual properties has not been determined so far [5]. The skin surface temperature is the result of heat transferred from the visceral organs to the skin surface. The aim of our study is to present a thermodynamic approach to the cerebrospinal fluid circulation taking into account the skin temperature distribution analyses on both sides of the neural tube in healthy volunteers. Di Chiro showed the existence of an active cerebrospinal fluid bulk flow, i.e., twodirectional flow in the subarachnoid space: downward in the dorsal part and upward in the ventral part of the spinal canal [6]. The cerebrospinal fluid bulk flow is under the influence of many factors such as intracranial pressure, arterial pressure, venous pressure, brain and cord motions, respiration and artery pulsations [7]. To our knowledge, there were no biomedical studies regarding thermodynamic aspects of the cerebrospinal circulation.

\section{Materials and Methods}

This work is a part of the research project Thermodynamic aspects of cerebrospinal fluid circulation. The study was carried out by the Chair of Sea and Environmental Physics, Institute of Physics at the University of Szczecin with cooperation of the Neurosurgery Department at the Public Provincial Hospital Complex in Szczecin. An approval to realize this study had been issued by the Bioethics Committee of the Regional Medical Chamber in Szczecin.

We performed skin temperatures measurements in 16 healthy adults, in 10 women and 6 men (mean age 38.8 
Table 1. Personal Data of Each Subject Recruited for A Thermal Skin Evaluation

\begin{tabular}{lll}
\hline No. & Sex & Age (years) \\
\hline 1 & F & 36 \\
2 & F & 34 \\
3 & F & 42 \\
4 & F & 33 \\
5 & M & 50 \\
6 & F & 51 \\
7 & F & 33 \\
8 & F & 42 \\
9 & F & 31 \\
10 & F & 51 \\
11 & M & 18 \\
12 & M & 40 \\
13 & M & 56 \\
14 & M & 25 \\
15 & F & 41 \\
16 & M & 38 \\
\hline
\end{tabular}

years; age range 18 - 56 years). Table 1 shows subjects' characteristics.

All volunteers had no medical history of acute or chronic disorders. The temperature was recorded by a non-contact thermometer on both sides of the spine, i.e., in the frontal region above glabella $\left(\mathrm{T}_{\mathrm{f}}\right)$ and in the lumbar region between spinous processes L4 and L5 ( $\mathrm{T}_{\mathrm{s}}$, in compliance with an acclimatization period of 15 minutes. We evaluated skin temperatures with the Thermofocus and the temperatures were recorded in degrees Celsius $\left({ }^{\circ} \mathrm{C}\right)$. The temperature probe shows values in increments of $0.1{ }^{\circ} \mathrm{C}$. The thermometer's infrared lens measures about $1.0 \mathrm{~cm}^{2}$ and is held $3 \mathrm{~cm}$ from the skin surface during measurement and is accurate to within $0.2{ }^{\circ} \mathrm{C}$. The room temperature was at $23.8^{\circ} \mathrm{C}$ during the study period. A two-tailed Student's t test for matched samples was used to compare temperature differences on both sides of the spine. The level of significance was set at $\mathrm{P}<0.05$.

\section{Results}

There were differences in skin temperature on both sides of the spine $(\mathrm{P}<0.001)$. The average temperature in the frontal region was $36.0 \pm 1.0^{\circ} \mathrm{C}$ (mean $\left.\pm \mathrm{SD}\right)$ and in the lumbar region $34.4 \pm 1.3{ }^{\circ} \mathrm{C}($ mean $\pm \mathrm{SD})$. Figure 1 shows temperature recordings in each person. Skin temperature in the frontal place ranged from $34.1{ }^{\circ} \mathrm{C}$ to $37.6{ }^{\circ} \mathrm{C}$ whereas in the lumbar one from $32{ }^{\circ} \mathrm{C}$ to $36.9^{\circ} \mathrm{C}$. The acquired data reveals a significant decrease in skin temperature between the frontal (median $36.0^{\circ} \mathrm{C}$ ) and the lumbar regions (median $34.6{ }^{\circ} \mathrm{C}$ ). Skin temperatures showed a $1.6 \pm 0.2^{\circ} \mathrm{C}($ mean $\pm \mathrm{SD})$ difference between the frontal region and the lumbar region. This thermal gradient ranges from $0.1{ }^{\circ} \mathrm{C}$ to $3.4^{\circ} \mathrm{C}$.

\section{Discussion}

Our study reveals that there was a significant $1.6^{\circ} \mathrm{C}$ difference in the mean skin temperature between the frontal and the lumbar regions. This data confirms the results reported by Zaproudina and coworkers suggesting that in healthy individuals the mean forehead area temperature is $34.1{ }^{\circ} \mathrm{C}$ (from $32.5^{\circ} \mathrm{C}$ to $35.7^{\circ} \mathrm{C}$ ) and the mean back temperature is $32.2{ }^{\circ} \mathrm{C}$ (from $30.5^{\circ} \mathrm{C}$ to $33.2{ }^{\circ} \mathrm{C}$ ), and so according to those authors the mean skin temperature difference between the both regions considered is about $1.9^{\circ} \mathrm{C}$ [8]. A primary factor leading to a difference between the frontal and the lumbar

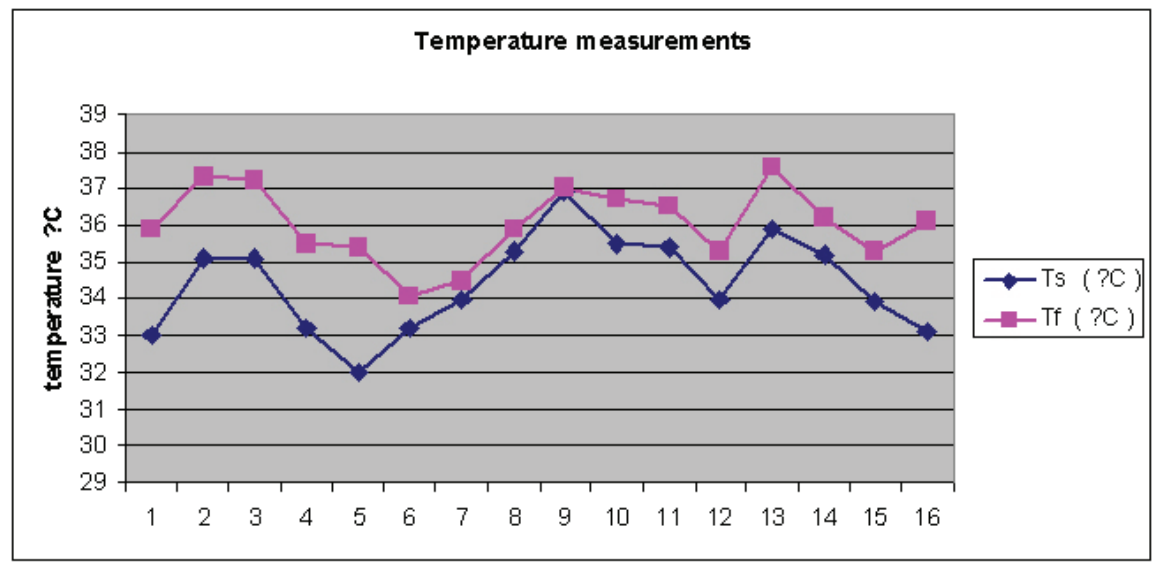

Figure 1. Temperature measurements $\left({ }^{\circ} \mathrm{C}\right)$ in each healthy volunteer on both sides of the neural tube, i.e., in the frontal and the lumbar regions. 


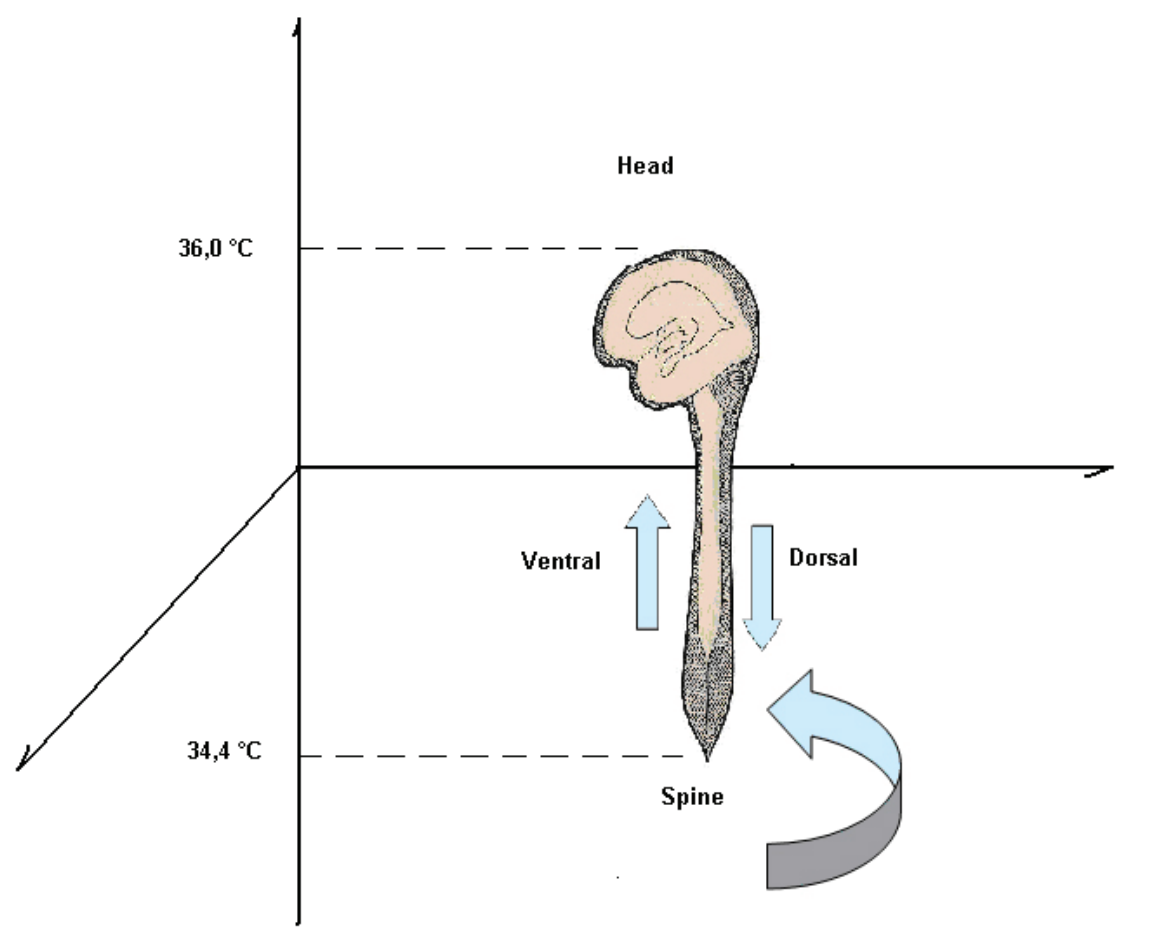

Figure 2. Temperature differences are the cause of the corkscrew motion of the cerebrospinal fluid in the subarachnoid space.

skin temperature is a discrepancy in depth of the internal organs and consequently the heat sources on both sides of the neural tube. The dermal, muscular and fatty layers taken together are much thicker in the lumbar region than in the frontal one. According to $\mathrm{Wu}$ and coworkers the skin surface temperature decreases by $1.2{ }^{\circ} \mathrm{C}$ for every $7 \mathrm{~cm}$ increase in the distance from the skin to the heat source [9].

What is now assumed is a concept of cerebrospinal fluid caudal flow in systole and cephalic flow in diastole $[10,11]$. Di Chiro showed the existence of an active cerebrospinal fluid bulk flow, i.e., two-directional flow in the subarachnoid space: downward in dorsal part and upward in ventral part of the spinal canal [6]. But the flow of cerebrospinal fluid upwards and downwards in the subarachnoid space around the cord and the brain is under a great consideration and a proven reason for the fluid circulation has not been very well understood and known until now.

A temperature difference between both ends of the subarachnoid space in the intracranial and the intracanal compartments can cause natural circulation to reach the thermal equilibrium. The authors state that from thermodynamic point of view the spinal canal can be divided into two spaces: the external space close to the skin and the internal one close to the visceral organs. The internal organ temperature reflects the core temperature. On the basis of a thermal study by Rajek and coworkers the core temperature is about $2-4$ ${ }^{\circ} \mathrm{C}$ higher than the skin temperature [1]. According to our results there is a $1.6{ }^{\circ} \mathrm{C}$ decrease in skin temperature just along the dorsal part of the spinal canal beginning from the head to the lumbar spine. The cerebrospinal fluid flow is a molecular motion as a consequence of the gravity force and the Brownian movements. The Brownian movements are diminishing due to temperature fall, the molecular particles' velocity is plummeting, the number of particles' collisions is decreasing and the distances between particles are dropping too. Thus, the local fluid density and its weight are increasing, which is the cause of the cerebrospinal fluid bulk flow directed downwardly.

The cerebrospinal fluid flow in the ventral space of the spinal canal is under the influence of internal organ heat. It is the reason for a greater temperature of cerebrospinal fluid in the ventral compartment compared to the dorsal side at the same level. It means that the fluid density at the same level is lesser in the internal space than in the external one because of volume increase. The higher in the spinal canal, the greater fluid temperature, and thus an increase in the Brownian motions as well as a decrease in fluid density. The Brownian motions are the driving forces for the cerebrospinal fluid bulk flow directed upwardly.

The cerebrospinal fluid in the external space of the spinal canal is flowing downwards because of temperature decrease and at the same time increase in weight and the gravity force. Since an increase in fluid temperature is greater within the internal space, the lifting force there is greater than in the external space. Thus, there is an increase in buoyant force in the internal space compared to the external one. Because 
between both spaces of the spinal canal the temperature difference exists, the density of cerebrospinal fluid is decreasing. As a consequence the buoyant force is increasing in a nonlinear manner causing corkscrew motion of cerebrospinal fluid. Figure 2 presents a schematic interaction of a temperature gradient both in the vertical and the axial planes. All in all, the authors propose a thermodynamic approach to the cerebrospinal fluid bulk flow in the subarachnoid space around the cord and the brain.

\section{Conclusions}

The mean skin surface temperature in the frontal region $\left(36.0^{\circ} \mathrm{C}\right)$ is significantly higher than in the lumbar region $\left(34.6^{\circ} \mathrm{C}\right)$. Skin temperature measurements showed a $1.6 \pm$ $0.2{ }^{\circ} \mathrm{C}$ (mean $\pm \mathrm{SD}$ ) difference between the frontal region and the lumbar region. The cerebrospinal fluid flow is a molecular motion as a consequence of the gravity force and the Brownian movements. The Brownian motions are the driving forces for the cerebrospinal fluid bulk flow directed upwardly. The gravity force is the driving force for the cerebrospinal fluid bulk flow directed downwardly. The buoyant force is increasing in a nonlinear manner causing corkscrew motions of cerebrospinal fluid.

\section{Acknowledgement}

The authors thank Patrycja Herbowska for help in the English translation of this manuscript.

\section{References}

1. Rajek A, Greif R, Sessler DI, Baumgardner J, Laciny $\mathrm{S}$, Bastanmehr H. Core cooling by central venous infu- sion of ice-cold (4 degrees $\mathrm{C}$ and 20 degrees C) fluid: isolation of core and peripheral thermal compartments. Anesthesiology. 2000;93(3):629-637.

2. Ramanathan NL. A New Weighting System for Mean Surface Temperature of the Human Body. J Appl Physiol. 1964;19:531-533.

3. Weinstein SA, Weinstein G, Weinstein EL, Gelb M. Facial thermography, basis, protocol, and clinical value. Cranio. 1991;9(3):201-211.

4. Houdas Y, Ring EFJ. Human Body Temperature: its Measurement and Regulation. London: Plenum Press, 1982.

5. Kempinska-Podhorodecka A, Szydlowski L, Knap O, Parafiniuk M. Application of thermovision in forensic medicine on the basis of the research carried out in Forensic Medicine Department, Pomeranian Medical University in Szczecin. Ann Acad Med Stetin. 2007;53 Suppl 2:107-112.

6. Di Chiro G. Observations on the circulation of the cerebrospinal fluid. Acta Radiol Diagn (Stockh). 1966;5:9881002.

7. Brodbelt A, Stoodley M. CSF pathways: a review. Br J Neurosurg. 2007;21(5):510-520.

8. Zaproudina N, Varmavuo V, Airaksinen O, Narhi M. Reproducibility of infrared thermography measurements in healthy individuals. Physiol Meas. 2008;29(4):515-524.

9. Wu Z, Liu HH, Lebanowski L, Liu Z, Hor PH. A basic step toward understanding skin surface temperature distributions caused by internal heat sources. Phys Med Biol. 2007;52(17):5379-5392.

10. Feinberg DA, Mark AS. Human brain motion and cerebrospinal fluid circulation demonstrated with MR velocity imaging. Radiology. 1987;163(3):793-799.

11. Greitz D, Hannerz J. A proposed model of cerebrospinal fluid circulation: observations with radionuclide cisternography. AJNR Am J Neuroradiol. 1996;17(3):431438. 